\title{
Tutor's role in conducting an urgency case by students in the collective health medical internship of a south Brazilian higher education institution
}

\begin{abstract}
In-service training as a practice of medical education emerged in Brazil around the 1940s and was regulated only in 1969. Intensive, continuous, and supervised training aims to increase practical experience in the training of new doctors. In the context of active methodologies, the tutor gives the protagonist role of the medical service to the students, encouraging them "to learn how to learn". In a Health Unit of Curitiba / PR, a student of the 10th medical period attended a patient with an acute abdomen, whose main diagnostic suspicion was acute cholecystitis. The patient had already undergone several urgent and emergency care equipment check-ups, but there was no referral to any more complex service for a definitive resolution of the condition. Through the electronic health system and connection to the Emergency Medical Service (SAMU, in Brazil), under the direct supervision of the tutor, the student took immediate medical conduct, referring the patient to a more complex service and requesting transportation directly from the Health Unit. By combining SNAPPS and Five-Step Micro-skills tools for students and teachers in outpatient medical education, we promoted the learner-tutor meeting for a clinical case discussion, development of new knowledge, recognition of positive attitudes and improvement of flaws. A trained and engaged tutor is of great value in developing student's autonomy, responsibility, and security during the learning process.
\end{abstract}

Keywords: tutor, medical education, urgency, collective health, medical internship, fever, nausea, vomiting, and hyporexia
Volume 4 Issue I - 2020

\author{
Jessica Belei Martins,' Fernanda Pombo \\ Rodriguez,' Marcelo Tsuyoshi Yamane,' \\ Vinícius Klettemberg Machado,' Leonardo \\ Campos Teixeira, ${ }^{2}$ Emile Fernandes Spinassi \\ Teixeir $^{2}$ \\ 'Medical student of the Faculty Pequeno Príncipe, Brazil \\ ${ }^{2}$ Family and Community Physician in Curitiba, Medicine's Teacher \\ in Faculty Pequeno Príncipe, Brazil
}

Correspondence: Jessica Belei Martins, Faculdades Pequeno Príncipe, Avenida Iguaçu, 333, Curitiba, Paraná, Brazil, Tel + 55 (43) 99649-9443, Email jessica.belei@hotmail.com

Received: November 28, 2019 | Published: January 24, 2020
Abbreviations: SAMU, serviço de atendimento médico de urgência - emergency medical care service; CFE, conselho federal de educação - federal council of education; SUS, sistema único de saúde - unified health system; PBL, problem based learning

\section{Introduction}

Medical education has long been a major challenge and cause for concern for teachers. In-service training as a medical teaching practice emerged in Brazil around the 1940s, with the Medical Internship being regulated only in 1969, through Document of the Federal Education Council (CFE). ${ }^{1}$ With this Resolution, the boarding school was conceptualized as the period of the end of undergraduate medical schools where medical schools were required to establish in their curricula a compulsory period of practical teaching in which students should receive continuous intensive training, under teachers' supervision, in health institution linked or not to the medical school. Document No. 8/1969 represented the only orientation for boarding school until the establishment of the Curriculum Guidelines for the 2001 Medical Undergraduate Course. ${ }^{2}$ With the enactment of the "Mais Médicos" Program ("More Doctors Program"), which provides for the training of human resources in the medical area for SUS (Sistema Único de Saúde - Unified Health System, translated to the English language), there is need to increase practical experience during the training process in order to broaden the insertion of the student in SUS practice scenarios. ${ }^{3}$ Therefore, during this period of the graduating period, it can be stated that immersion in daily practice activities is of great importance in the formation of new professional doctors.

In the context of the Problem Based Learning (PBL) methodology, Problem-Based Learning (PBL), the tutor's role designates the concerned teacher in teaching the student "to learn how to learn". In this scenario, the tutor appears as a facilitator of the studentcentered teaching-learning process, reviewing professional practice without neglecting the role of assessing the student. Trained tutors managing tutorials of small groups help students to obtain maximum learning benefits. ${ }^{4}$ In addition to clinical competence and the ability to help in the "to learn how to learn" process, the tutor must have an understanding of the professional practice and encourage students' personal and professional development. ${ }^{5,6,7}$ In this scenario, the objective of this paper is to report the experience of tutoring, from the point of view of the students, in conducting an emergency case in a Primary Health Care Service in Curitiba, a city in the south of Brazil.

\section{Context and case study}

In the city of Curitiba / PR, the patients' entry into the care network of urgency and emergency services occurs mainly by the Emergency Care Units. When there is a need for more complex care than available at the centers, referral to greater complexity is made by the Metropolitan Regulation Center, through the electronic health system. The previous understanding of this background is important for the comprehension of the case. Our case is of a female patient, 31 years old, no comorbidities, no medication. She arrives at the Primary Care Service and is assisted by F., a student on the $10^{\text {th }}$ semester of medical school. She complains of severe pain in her right hypochondrium that has been for five days, associated with fever, nausea, vomiting, and hyporexia. Her personal medical history: a caesarean section and tubal ligation, one year before. The patient has sought care in three Emergency Care Units in recent days, where intravenous opioid analgesia had been performed, with partial improvement of pain and discharge with outpatient analgesia. 
On physical examination, the patient was in regular general condition, antalgic position, pain facies, febrile (had used dipyrone two hours earlier), anicteric. Distended abdomen, tympanic, little airborne noises audible, signs of positive Murphy, Blumberg and Giordano negative. Brings with her an abdominal ultrasound performed by herself (with no medical requirement), showing cholecystolithiasis with calculi up to $8 \mathrm{~mm}$ (sic). The diagnostic hypothesis was acute cholecystitis. An immediate intravenous analgesia was performed and, through the Metropolitan Regulation Center by the electronic health system, a hospital was requested for definitive treatment of the condition. After about 90 minutes, the Regulation Center staff made contact informing us about availability at the University Hospital of the Metropolitan Region. An ambulance transport was also requested for the patient, from the Primary Care Service to the hospital, with no need of going through the intermediary emergency service at the Emergency Care Unit.

\section{Results}

In the Primary Care Service where the internship happens, the Medical Professional Service remains open for urgent consultations. The 10th-semester students attend to scheduled cases and discuss them with the teacher. They perform anamnesis and unaccompanied clinical examination then propos diagnoses and their differentials, besides the conduct and therapeutic plan. If the teacher agrees with the proposed plan, it is carried out. After presenting and summarizing the above case, the tutor provoked the reasoning of the student concerned through the questions "What do you think is going on with the patient?", "What information did you use to reach this conclusion?" and "What do you propose for this case?" By answering these questions, he encouraged clinical reasoning in order the student to present a solution for the condition. When the student proposed immediate intravenous analgesia and transfer to a reference surgery, the tutor agreed with the suggested conduct and questioned how this transfer could be accomplished, inspiring reflection, and offering freedom for the student's clinical decision.

Anxious, tachycardic, and with the speakerphone on, F. decided to contact SAMU (Emergency Medical Care Service). He described the case to the regulator physician, requesting transportation and vacancy in the surgical setting for the patient in a hospital. The regulator informed that the patient should be transferred to the Emergency Care Unit and, only in this service, be inserted in the Emergency Care Unit through the electronic health system. The tutor remained silent and allowed the student to fully conduct the conversation with the regulator, as he did not deem it necessary to interfere. At the end of the call, the teacher commented: "You did the right thing, it was great". As the patient had previously sought care in several Emergency Care Units and had not been transferred to the proper service, it was asked in a group of four students, the possibility of referring her directly from the Primary Care Service to the hospital.

Guided by the teacher, we managed to achieve it. For conference purposes, F. called again and questioned the regulator physician if the patient was enrolled in the Metropolitan Regulation Center. The SAMU regulator also informed that they would make telephone contact when a surgical setting was available and advised the permanence of the patient in the Primary Care Service. Again, the tutor remained silent as there were no considerations to add beyond those proposed by the student. After a while, the Metropolitan Regulation Center contacted F. directly informing hospital place availability and confirming the patient's transfer by ambulance to a university hospital in the metropolitan area. All clinical and bureaucratic procedures related to care were performed by the student and supervised by the tutor, from the writing in the medical record to the case report, via telephone, to the Regulation Center. For academic discussion the next day, F. brought a review on urgency and emergency services in the Primary Health Care.

\section{Discussion}

In outpatient clinics it is common to observe the limited participation of the student in discussions, presenting the history, clinical data, and complementary exams and awaiting the preceptor's reasoning and plan. Yet, in these situations the student's prior knowledge and doubts are ignored, putting him or her in a passive learning position. When using a strategy with the learner in the focus of the discussion and conduct of the case the teacher or teachers move him or her to have an active stance and take charge of the clinical case, generating learning, and developing security for their professional performance. For breaking this cycle of no responsibility of the student, SNAPPS and Five-Step Micro-Skills tools can be used for students and teachers, respectively. It promotes the meeting between the learner and the tutor for discussion of a clinical case, for the development of new knowledge, recognition of positive attitudes and improvement in case of flaws. ${ }^{8,9}$

The SNAPPS mnemonic (summarize, number, analyze, ask, plan and select) is used as a tool to guide the steps and to be followed by the student in the case report, enabling the identification of flaws and strengths by the teacher. The first step guides you to briefly summarize the history and clinical examination, including results of further examinations. The student in case here described the history and physical examination to the preceptor, including an abdominal USG recently performed. Following, the tool suggests numbering two or three most relevant possibilities for the diagnosis and its differentials, which was not performed by the learner, who reported only "acute abdomen" as a hypothesis. However, it is known that such entity has several possible diagnoses, making it possible to list a lot of differentials. For the analysis of differentials, one should compare and judge the findings that speak for or against each possibility listed above. With the help of the physical examination, F. strengthened the suspicion of acute cholecystitis, and ruled out diagnostic hypotheses as cholangitis, appendicitis, and pyelonephritis. Based on abdominal ultrasound recently performed, the hypothesis of acute cholecystitis could be confirmed.

The next step would be to ask the tutor about some uncertainties, difficulties or possible alternative approaches and clarifying doubt. F. had no doubt therefore this step does not apply to the situation. To plan problem management of the patient's health, the academic should be encouraged by the tutor to therapeutic proposals. The therapeutic approach of immediate analgesia and transfer for a tertiary hospital was proposed and put into practice by the student. The last step of the tool suggests selecting a case-related topic for the study. It is not necessary to review the entire clinical entity presented by the patient, only identify a study topic based on the case presented. For being a new situation in his academic life, F. reviewed the attendance of urgency and emergency services in Primary Health Care. The FiveStep Micro-skills approach consists of a practical model of clinical teaching, based on five tutor sequences. Such a model was designed for a discussion for approximately five minutes and may vary as 
needed by the learner and complexity of the case. This learning tool describes five teacher's performances:

I. Establish commitment, listen to the student and their considerations;

II. Investigate how to identify and support the reasoning of the learner;

III. Make a positive feedback, signaling the acts of behavior and technical experts;

IV. Teach general rules, identifying opportunities for learning from gaps or flaws in the process;

V. Correct mistakes and suggest improvements so they don't happen again. Major flaws must be corrected later, in a calm and private environment. ${ }^{9}$

All steps of this approach are followed by the teacher in the routine internship in Public Health, but what drew the most attention in this case, was the freedom offered to those who study their conduct and had contact with the "life emergency" situation in Primary Health Care. Students involved in this service, inserted in practice scenarios and being exposed to everyday situations are helped to develop a sense of responsibility, autonomy, and confidence for adverse times.

\section{Conclusion}

The teaching of the medical profession has been an object of study and a cause of concern for many years. A trained, mentored, and engaged tutor is of great value for the development of student's autonomy, responsibility, and safety during the learning process.

\section{Conflicts of interest}

Author declares there is no conflict of interest.

\section{References}

1. Legislação do ensino superior; índice remissivo e jurisprudência. Resolução n $^{\circ}$ 8, de 8 de outubro de 1969. 1973.

2. Diretrizes Curriculares Nacionais do Curso de Graduação em Medicina. Resolução no 4, de 7 de novembro de 2001. 2001.

3. Programa Mais Médicos, altera as Leis no 8.745, de 9 de dezembro de 1993, e no 6.932, de 7 de julho de 1981, e dá outras providências. Lei no 12.871, de 22 de outubro de 2013. 2013.

4. Haque Z, Ayoob Z, Imtiaz F. Role of tutors training in delivering effective medical education. Journal of the Dow University of Health Sciences. 2008;2(2):60-64.

5. Botti SH de O, Rego S. Preceptor, supervisor, tutor e mentor: quais são seus papéis?. Revista Brasileira de Educação Médica. 2008;32(3):363373.

6. Associação Brasileira de Educação Médica. O internato nas escolas médicas brasileiras. 1984. p. 1-68.

7. Khaw C, Raw L. The outcomes and acceptability of near-peer teaching among medical students in clinical skills. International Journal of Medical Education. 2016;7:188-194.

8. Wolpaw TM, Wolpaw DR, Papp KK. SNAPPS: a learner-centered model for outpatient education. Acad Med. 2003;78(9):893-898.

9. Neher JO, Gordon KC, Meyer B, et al. A Five-Step "Microskills" Model of Clinical Teaching. J Am Board Fam Pract. 1992;5(4):419-424.

\section{Acknowledgments}

None. 